\title{
Managing clinical environments, equipment and materials
}

\author{
Sue Dallas, Marie Jones and Elizabeth Mullineaux
}

\section{This chapter is designed to give information on:}

Environmental conditions that should be maintained in each clinical area

Methods of prevention of spread of infection, including methods of cleaning

- Methods of waste disposal

- Isolation and barrier nursing

The management of stock in the veterinary practice

\section{The inpatient environment}

Animals are hospitalized in order to:

- Be observed

- Have surgical procedures carried out

- Have medical procedures carried out

- Be nursed

- Have samples collected from them.

In order for veterinary staff to do this, the environment must be correct. To ensure a high standard of care, there must be adequate facilities, equipment and human resources.

Locations within the practice for the care of patients include:

Consultation rooms

- Operating theatre

- Preparation/triage rooms

Recovery area

Kennels

Grooming area

Exercise areas

Kitchen/food preparation room.

General considerations for the inpatient include:

- Environmental temperature

- Hygiene and cleaning

- Light, heat, ventilation, noise and security.

\section{Environmental temperature}

In most mammals and birds, body temperature is regulated within the ideal thermoneutral zone. This varies between species to allow for the working of the internal body environment of each, and the balance attained is known as homeostasis.

Reptiles and amphibians interact with their environmental temperature to maintain a body temperature that is optimal for the particular species, given the opportunity to do so. Thus, monitoring of their body temperature is not always necessary.

However, all species, whatever means they use to control their own body temperature, sometimes need help. When an animal is conscious and healthy, its internal mechanisms are functioning; but when it is ill or injured, it may need assistance from the nursing environment.

In most clinical situations, it is usually desirable to maintain an animal's normal or optimal body temperature. Patients in the veterinary clinic that are unable, for a variety of reasons, to maintain their own body temperature within normal limits will benefit (often dramatically) when the environmental temperature is either raised or lowered to suit their special needs.

Methods of assisting patients to raise their body temperature include:

\footnotetext{
- Heat pads

- Bubblewrap

Water-circulating pads
} 
- Incubators

- Hot-water bottles (well wrapped)

- Ceramic heat lamps (especially for reptiles)

- Lightweight blankets

- Space blankets

- Synthetic fleece

- Beanbags.

Methods used to lower body temperature include:

- Cool pads

- Fans

- Air conditioning.

In each clinical area of the veterinary practice temperatures should be maintained appropriately; temperature fluctuations should be monitored and recorded using maximum-minimum thermometers. The ideal range is $18-21^{\circ} \mathrm{C}$, and the temperature should not fall below $15.5^{\circ} \mathrm{C}$.

\section{Prevention of the spread of infection}

\section{How disease spreads}

Disease is spread from one animal to another by various methods (see also Chapter 2). Microbes leave the body in or on:

- Oral, nasal and ocular discharges (e.g. rabies via the saliva; feline respiratory diseases and distemper via ocular and nasal discharge)

- Urine (e.g. leptospirosis and hepatitis)

- Vomit (e.g. canine parvovirus)

- Blood (e.g. microorganisms transmitted by fleas to another animal)

- Skin surface (e.g. surface bacteria and fungi such as ringworm)

- Milk from mother to offspring (e.g. some worms, some viruses).

The microbes are passed on from one animal to another, sometimes by a carrier animal. These animals do not show clinical signs of disease but are individuals that:

- Have had the disease and recovered (convalescent carriers)

- Never show clinical signs of the disease (healthy carriers).

Both types will shed the disease-carrying microbes into the environment, putting other animals at risk. Microbes are passed from one animal to another by means of:

- Direct contact - parts of the bodies of two animals come into contact (e.g. nose to nose or nose to anus)

- Indirect contact - the contact is with an inanimate object (e.g. bedding, water bowl or lamp post)

- Aerosol transmission - through the air, in the form of droplets from sneezing, coughing or using air currents
- Contaminated food or water - contaminated by urine and faeces of passing rodents or other animals (due to incorrect storage of dried foods)

- Carrier animals - shedding microbes in discharges, urine or faeces yet unaffected themselves (e.g. canine hepatitis).

\section{Development of disease}

\section{Entry into a new host}

Routes of entry include the following.

- Eating:

- Infected food or water

- Contact with contaminated food/water bowls

- Eating faeces (coprophagia)

- Eating the disease carrier (e.g. flea, while grooming).

- Inhalation:

- Breathing in airborne microbes, or sniffing contaminated surfaces.

- Through the skin:

- Wound

- Scratch

- Insect bite

- Subsurface mite (e.g. Sarcoptes).

- Via damaged mucous membranes:

- Mouth

- Nose

- Eye.

\section{Infection}

If the microorganism has entered the host animal and overcome its resistance, infection may ensue. Some infections are confined to a restricted area (e.g. abscesses); others are called systemic because they spread through the whole body via the bloodstream.

\section{Resistance to infection}

Individual resistance will depend on:

- Age

- Nutritional state (too thin or overweight)

- Skin being intact

- Vaccination status

- Immune response and white blood cell activity.

\section{Incubation}

Incubation refers to the time between the animal receiving the microbe and showing clinical signs of disease.

\section{Methods used to control disease}

- Avoid direct contact with infected animals (use of isolation, see later).

- Maintain high levels of hygiene/disinfection in the animal's environment.

- Reduce the number of animals kept within the same air space, or improve the efficiency of air movement to reduce aerosol transmission.

- Provide early and effective treatment of infected animals to prevent others becoming infected.

- Control parasites to prevent passing of disease from one animal to another.

- Maintain vaccination status of animals and staff. 


\section{Cleaning and maintaining clinical environments}

The practice hospital environment may house high concentrations of microorganisms that are potentially pathogenic (i.e. can cause disease). When patients are injured or diseased, they are even more at risk because of a decreased resistance to infection. Every effort must be made to decrease the microbe population in order to safeguard patients.

The aims are to:

- Eliminate or control sources of disease

- Prevent transmission of disease

- Increase host resistance to disease.

Methods of achieving these aims include:

- Isolation and quarantine

- Vaccination

- Improved diet

- Hygiene

- Chemotherapeutic agents

- Euthanasia of animals with uncontrollable infections.

Sources and transmission of disease can be controlled by:

- Improved ventilation

- Physical cleaning

- Chemical disinfectants and antiseptics

- The use of protective clothing (plastic disposable aprons and gloves; see Figure 4.12).

Standards will be adjusted according to the area within the hospital practice.

\section{General cleaning}

In the case of general cleaning equipment (to include commercial cleaners), the level of care is standard.

\section{Mopping}

If mops are used for washing floors, the following rules apply.

- Mop heads should be washed daily in the washing machine $\left(>40^{\circ} \mathrm{C}\right)$ and dried.

- If used more than once daily, they should be soaked for 30 minutes in a bucket of disinfectant.
- They should never be left standing in soaking solution for any longer than 30 minutes.

- They should be wrung out thoroughly before use on the floors.

\section{Cleaning a floor with a mop}

- Move the mop from left to right across the body; never push it back and forth in front of you.

- The mop head should be agitated in the disinfectant solution and wrung out before proceeding to clean.

- Start with the area of floor furthest from the door.

- When the area immediately around you has been cleaned, move and repeat the mop rinsing for a new area.

- No one should be allowed to walk on the floor until it is dry.

- Change the disinfectant solution between rooms, or more frequently if the floor is heavily soiled.

- A separate mop or other cleaning equipment should be used in areas where high standards of clinical cleanliness are important (e.g. theatre).

\section{Cleaning surfaces}

Checks should be made throughout the day on:

- Doors

- Cabinet/cupboard doors

- Walls

- Lighting

- Monitor/keyboards, if present.

Spot-cleaning should be carried out as required, using the appropriate solutions. Cleaning between each patient must be carried out on:

- Tables

- Surfaces

- Equipment used.

To prevent spread of disease, the appropriate disinfectant (Figure 4.1) or antiseptic solution on a disposable cloth or wipe is used and protective clothing is worn to protect staff and other patients.

\begin{tabular}{l|l|l|l|l}
\hline $\begin{array}{l}\text { Type/active } \\
\text { ingredient }\end{array}$ & $\begin{array}{l}\text { Examples of } \\
\text { commercial } \\
\text { products }\end{array}$ & $\begin{array}{l}\text { Formulation and } \\
\text { recommended } \\
\text { use }\end{array}$ & Advantages & Disadvantages \\
\hline Phenol compound & Jeyes & $\begin{array}{l}\text { Liquid } \\
- \text { environment }\end{array}$ & $\begin{array}{l}\text { Good activity against a range of } \\
\text { bacteria; inexpensive }\end{array}$ & $\begin{array}{l}\text { Variable activity against viruses; } \\
\text { poor activity against spores. } \\
\text { Toxic to cats }\end{array}$ \\
\hline Chloroxylenol & Dettol & $\begin{array}{l}\text { Liquid } \\
\text { - environment } \\
\text { and skin }\end{array}$ & $\begin{array}{l}\text { Good activity against } \\
\text { Gram-positive bacteria }\end{array}$ & $\begin{array}{l}\text { Inactivated by hard water/ } \\
\text { organic matter; poor activity } \\
\text { against Gram-negative bacteria }\end{array}$ \\
\hline
\end{tabular}




\begin{tabular}{l|l|l|l|l}
\hline $\begin{array}{l}\text { Type/active } \\
\text { ingredient }\end{array}$ & $\begin{array}{l}\text { Examples of } \\
\text { commercial } \\
\text { products }\end{array}$ & $\begin{array}{l}\text { Formulation and } \\
\text { recommended } \\
\text { use }\end{array}$ & Advantages & Disadvantages \\
\hline Hypochlorites (bleach) & Domestos & $\begin{array}{l}\text { Liquid } \\
- \text { environment }\end{array}$ & $\begin{array}{l}\text { Effective against bacteria, } \\
\text { fungi, viruses and spores; } \\
\text { inexpensive }\end{array}$ & $\begin{array}{l}\text { Corrosive; strong smell; } \\
\text { inactivated by organic matter; } \\
\text { can give off gas if mixed with } \\
\text { urine }\end{array}$ \\
\hline $\begin{array}{l}\text { Halogenated tertiary } \\
\text { amines (contain } \\
\text { quaternary ammonium } \\
\text { compounds) }\end{array}$ & $\begin{array}{l}\text { Trigene, } \\
\text { Vetaclean }\end{array}$ & $\begin{array}{l}\text { Liquid } \\
- \text { environment }\end{array}$ & $\begin{array}{l}\text { Good activity against bacteria, } \\
\text { fungi and viruses; low toxicity; } \\
\text { low corrosion }\end{array}$ & Inactivated by hard water \\
\hline $\begin{array}{l}\text { lodine / lodophors } \\
\text { Peroxygen compounds }\end{array}$ & Pevidine & $\begin{array}{l}\text { Liquid - topical } \\
\text { skin application }\end{array}$ & $\begin{array}{l}\text { Good activity against spores; } \\
\text { wide range of activity }\end{array}$ & May stain; allergic reactions \\
\hline $\begin{array}{l}\text { Aldehydes } \\
\text { (glutaraldehyde) }\end{array}$ & $\begin{array}{l}\text { Cidex, } \\
\text { Parvocide }\end{array}$ & $\begin{array}{l}\text { Liquid } \\
- \text { environment }\end{array}$ & $\begin{array}{l}\text { Active against a wide range of } \\
\text { microorganisms; fast acting }\end{array}$ & $\begin{array}{l}\text { Activity reduced by organic } \\
\text { matter; corrosive to metal; irritant }\end{array}$ \\
\hline $\begin{array}{l}\text { Alcohol } \\
\text { organisms }\end{array}$ & Surgical spirit & $\begin{array}{l}\text { Liquid - skin and } \\
\text { environment }\end{array}$ & $\begin{array}{l}\text { Good activity against bacteria } \\
\text { and fungi; fast acting }\end{array}$ & $\begin{array}{l}\text { Flammable; not sporicidal; } \\
\text { inactivated by organic matter; }\end{array}$ \\
\hline $\begin{array}{l}\text { Biguanides } \\
\text { can be irritant }\end{array}$
\end{tabular}

4.1 (continued) Disinfectants and antiseptics.

\section{Different inpatient areas}

\section{Consultation rooms}

These are the outpatient, examination and consultation zones (Figure 4.2). They are normally decorated in similar warm tones to the clinic reception area.

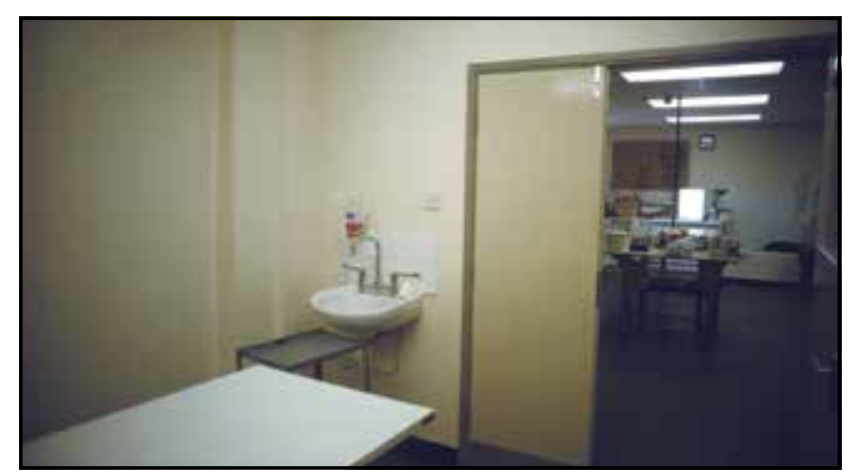

4.2 Consultation room, with a wide door leading to the treatment area.

It is important to maintain a high standard of repair and hygiene here because this is where the client will spend the greatest amount of time. Excessive fittings are normally avoided; those that are in place are necessary for the purposes of examination of patients.

Fixtures might include:

- Examination table (either floor-mounted or cantilevered from the wall)

- Wall-mounted shelf (with drawers for equipment)

- Hand washbasin

- Wall-mounted antiseptic solution dispenser
- Paper towel dispenser

- Appropriate bins or containers for clinical and non-clinical waste (see later)

- X-ray viewer

- Wall-mounted ophthalmoscope/auriscope.

It is in the consultation room that the client and veterinary surgeon meet, often for the first time. It is important that everything required for a thorough examination is to hand and has been cleaned and disinfected between patients. For this reason, the ideal design allows the veterinary surgeon to use two consultation rooms, with a separate dispensary (Figure 4.3). This type of layout enables each soiled room in turn to be thoroughly cleaned between clients (Figure 4.4) without hindering consultations.

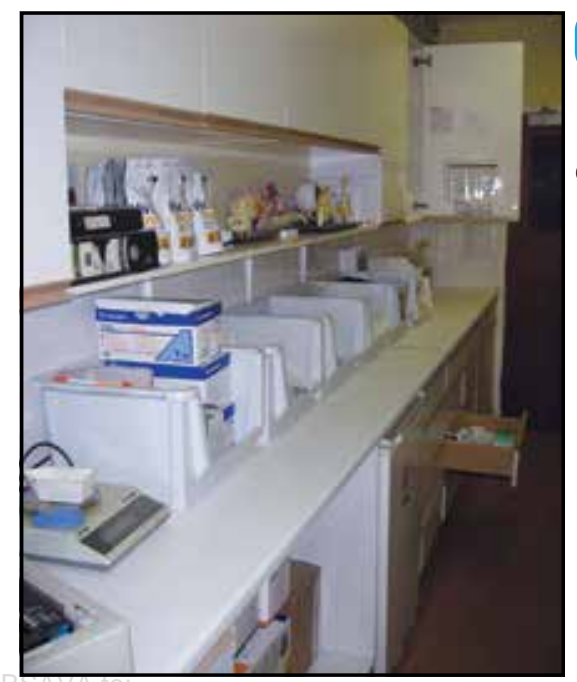

\section{3}

Dispensary area between two consultation rooms. 


\begin{tabular}{l}
\hline Between clients \\
Clean and disinfect the surface of the examination table \\
Spot-clean other surfaces if soiled \\
Check and clean soiled instruments \\
Collect up and remove soiled dressings or bandage materials \\
\hline Between consultation surgeries \\
\hline Clean and disinfect all surfaces (morning, afternoon and \\
evening) \\
Collect used instruments and sterilize or clean them \\
Dispose of all waste in the appropriate containers, bins or \\
bags (see Figure 4.11) \\
Empty and disinfect bins \\
Restock (as required): \\
- Selection of curved and straight scissors \\
- Dressings and bandages \\
- Cotton wool \\
- Antiseptic solutions \\
- Stethoscope \\
- Thermometer \\
- Selection of forceps \\
- Stitch cutters \\
- Paper towels
\end{tabular}

4.4 Cleaning routines for consultation rooms.

\section{Preparation and triage area}

This central area is one of the most important rooms in a modern veterinary clinic. It is a non-sterile area, but because of the variety of patients passing through the room it is essential to maintain a high level of hygiene.

Triage (examination and rapid classification of a case) may also take place here (Figure 4.5). It is a multipurpose room in which patients from the ward, kennels and consultation rooms will:

- Receive medication and treatment

- Have samples collected for diagnostic procedures

- Be examined

- Have bandages, splints or casts removed or changed

- Be prepared for surgical procedures.

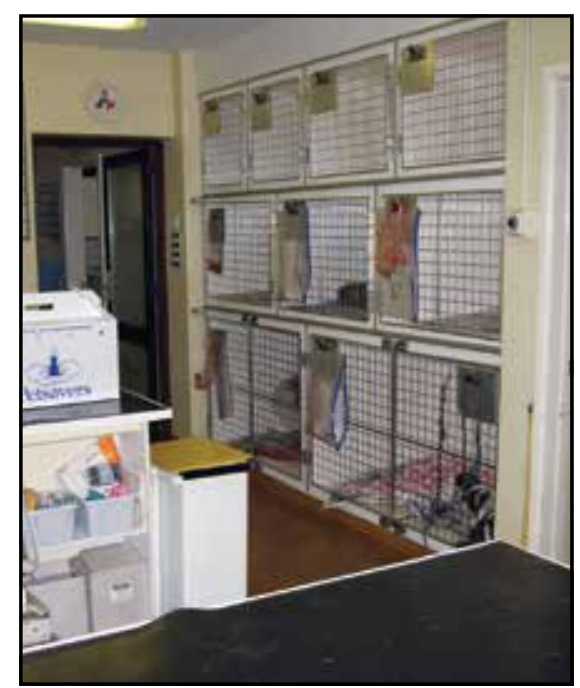

Preparation and triage room.
It is important that this is a secure area, ideally with a double self-closing door system to be passed through before escape is possible. Instructions to all staff about the opening and closing of these doors are usually displayed on a nearby wall.

- Surfaces in the preparation/triage area must be of a high standard, allowing easy disinfection and excellent hygiene.

- The walls should be covered with durable low-maintenance material, allowing regular wiping down.

- Floors have to withstand constant traffic (staff and patients) and frequent cleaning.

- Considerable storage space is required for both large equipment and disposable materials.

- Due to the many functions of this area, it is frequently up to four times the size of the clinic's operating theatre.

- Preparation for surgical procedures (anaesthetic induction and clipping up) requires a gas scavenging system, an oxygen supply, an anaesthetic machine and a vacuum facility to collect hair.

- Good lighting is essential:

- Fluorescent lights inset into the ceiling with diffuser panels for general room light are an alternative to normal daylight

- Spotlights (with a dimmer facility) over the treatment tables ensure good light levels in the key work areas of the room.

- Ventilation systems, via air conditioning using forced intake and extraction of atmosphere, should be installed; they will also provide constant temperature and humidity.

- Windows should not be present, unless escapeproof and with blinds.

- In order to reduce noise levels, high-set windows should be double-glazed; purpose-lagged wall panels and fire doors should be kept shut to prevent the transfer of sound through the clinic or outside the clinic.

Cleaning routines for the preparation/triage area are shown in Figure 4.6.

The preparation/triage room is always sited near the theatre suite for easy movement of patients. Also nearby are:

\section{- Surgical team's scrub-up area \\ - Sterilizers \\ Instrument cleaning and packing facility}

Due to the many roles that this area plays in the work of the clinic, it is essential that order and organization of equipment and disposable materials are well established. Systems include:

- Good shelving

- Cupboards and cabinets with obvious labels concerning equipment and use

- Sterilizing dates and equipment named on all packs

- Stock lists required, with quantities. 


\section{Between patient preparations or treatments}

Dispose of waste materials and body fluids as clinical waste (see Figure 4.11)

Clean the clipper blades and clippers

Check the walls, surfaces, worktops and treatment table and spot-clean with dilute disinfectant (see Figure 4.1)

Check the vacuum collection bag or container and empty it if necessary

Spot-clean the floor

Check levels of disposables

\section{After preparation/treatment sessions}

Dispose of all waste material; disinfect bins and fit new liners Wipe down all surfaces with dilute disinfectant

Restock cupboards

Check equipment (e.g. clippers and blades)

Refill dispensers for hand-cleaners and antiseptics

Clean all sinks

Replace towels and paper towel rolls

Cleaning routines for the preparation/triage area.

\section{Recovery area}

On completion of surgical procedures, patients recover consciousness in an area where staff are able to monitor and observe them (Figure 4.7).

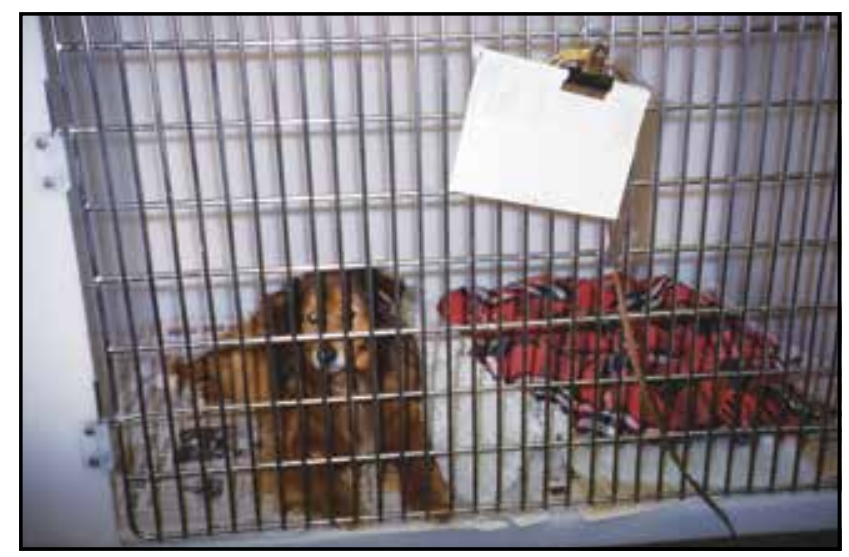

Recovery kennel, allowing good patient observation.

These animals should not be disturbed by unnecessary cleaning routines, but it is essential to allow thorough cleaning to take place at some point in each day, when patients have been moved to the ward kennels.

Patients in the recovery stage may vomit, defecate, urinate or salivate. These body fluids must be removed immediately, and disposed of in the correct manner by staff wearing protective clothing.

Cleaning should include the following routines:

- Dispose of waste; disinfect bins and replace plastic liners

- Wipe down all surfaces and equipment such as drip stands

- Clean and disinfect recovery areas

- Check supplies of disposable materials and restock

- Clean the floor.

\section{Kennels and wards}

Patients are moved from the recovery area to an inpatient ward (Figure 4.8). These wards are normally situated as far as possible from the consulting and reception areas of the clinic.

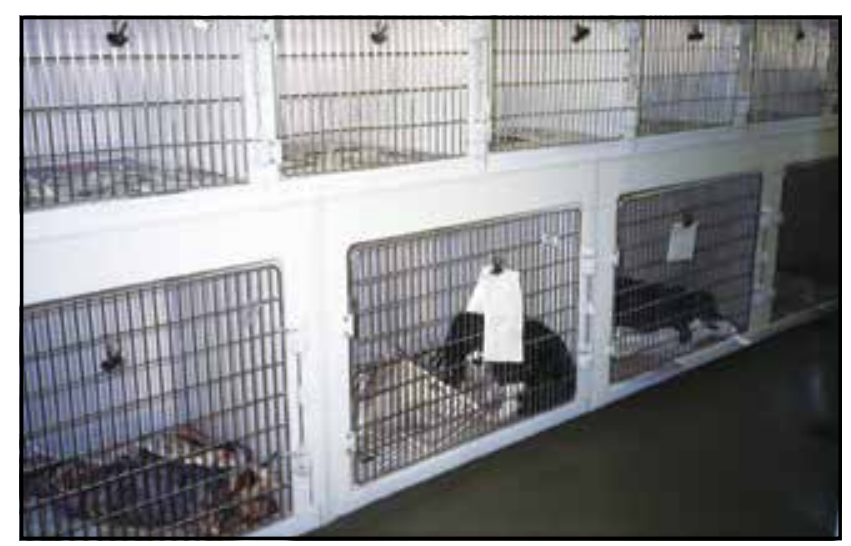

4.8

Tiered hospital kennels in an inpatient ward.

- Kennel wards must:

- Be durable

- Be secure

- Be easy to clean

- Retain heat

- Allow good observation of the patient.

- Kennels must be of the correct size for the type of patient housed and should be made of a material that is non-permeable and is easy to clean and disinfect.

- Heating and ventilation are important to assist in maintaining a patient's body temperature, while providing good oxygen levels in the room atmosphere.

- For further improvement of the atmosphere, a combination of air conditioning and scavenging systems may be used.

- Noise from inpatients is controlled by good soundproofing. Materials used to isolate the noise in the animal ward area include:

- Acoustic tiles fitted to ceiling and floor

- Walls well insulated and lagged

- Double-glazing fitted to any window

- Self-closing internal doors.

The daily cleaning routine for kennels and wards is shown in Figure 4.9.

- Remove waste from all bins; replace the plastic liner

- Clean and disinfect walls

- Spot-clean surfaces, doors, cupboard doors, light fixtures, drip stands and any other items routinely kept in this area

- Check and restock any disposable materials

- Clean and disinfect the sink (if any)

- Clean and disinfect the floor

- Disinfect and store cleaning equipment

- Launder all used bedding on high temperature setting (minimum $40^{\circ} \mathrm{C}$ )

Daily cleaning routine for kennels and wards. 
Sick and recovering animals often cannot control urination and defecation; therefore, more frequent attention and cleaning of a soiled kennel is required (for details on bedding materials, see the BSAVA Manual of Practical Animal Care).

Before disposal of urine and faeces, it is important to check whether a sample is required. If a sample has been requested by the attending veterinary surgeon, it should be collected in an appropriate container, sealed, labelled and refrigerated. There should be a note on the case card that collection has taken place.

\section{Exercise run}

For reasons of security, exercise areas should be adjacent to the kennel wards with escape-proof fences or walls between the two (Figure 4.10). The run area is often located within an insulated area of the clinic for control of environmental temperature and noise levels.

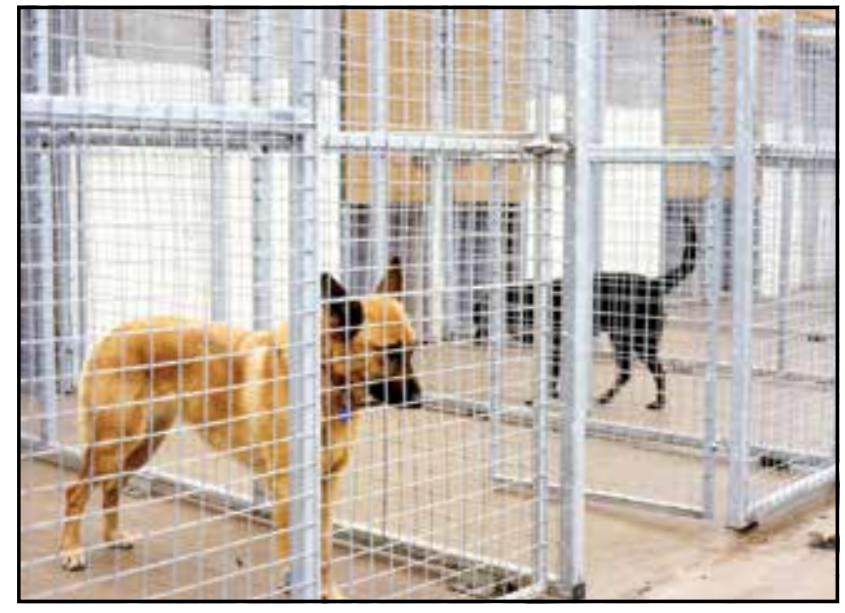

4.10 Individual run areas for long-stay patients.

\section{Grooming facilities}

Grooming facilities may be attached to the clinic as an additional customer service and to enable patients to be groomed as a part of essential routine care before discharge. A bath tub, grooming table and dryers are required. The grooming clippers, combs and brushes are stored and cared for here. (For details on grooming, see the BSAVA Manual of Practical Animal Care.)

\section{Kitchen/food preparation area}

The kitchen is where food is stored and prepared for inpatients.

- With a variety of species being catered for, a range of tinned, dry and fresh foods needs to be stored:

- The dry foods must be stored in dry rodentproof containers and labelled for content

- A storage area is needed for the various types of tinned food, with easy viewing for stock control

- A refrigerator should be available for the storage of part-used tinned foods, perishables and fresh foods.

- The work/preparation surfaces must be durable and easy to clean and disinfect.

- There should be a good-sized sink unit, with drainer, for the preparation and washing of fresh leafy foods.

- There needs to be a sufficient area of work surfaces to accommodate the washing up, drying and storage of bowls and containers.

\section{Waste disposal}

All waste materials must be disposed of safely and in accordance with legal requirements (Figure 4.11).

\begin{tabular}{|c|c|c|}
\hline Type of waste & Things included & Type of disposal \\
\hline General waste & Paper; cardboard; kitchen waste & $\begin{array}{l}\text { Recycle if possible. Otherwise dispose of via local } \\
\text { council usually in blue or black bags }\end{array}$ \\
\hline $\begin{array}{l}\text { Non-hazardous } \\
\text { veterinary healthcare } \\
\text { waste }\end{array}$ & $\begin{array}{l}\text { Blood-stained theatre waste; kennel waste; } \\
\text { consulting room waste }\end{array}$ & Yellow and black striped ('wasp' or 'tiger') bags \\
\hline $\begin{array}{l}\text { Hazardous veterinary } \\
\text { healthcare waste }\end{array}$ & $\begin{array}{l}\text { Blood-stained, faecal contaminated or body } \\
\text { fluid-contaminated waste from animals } \\
\text { with diseases infectious to other animals or } \\
\text { humans }\end{array}$ & $\begin{array}{l}\text { Orange clinical waste bags } \\
\text { OR } \\
\text { Yellow clinical waste bags or bins }\end{array}$ \\
\hline 'Sharps' & Needles; blades; broken contaminated glass & 'Sharps' bin, usually yellow with a white or red lid \\
\hline Chemotherapeutic waste & Contaminated needles, vials, giving sets & 'Chemotherapeutic' bin, with a purple or black lid \\
\hline \multirow[t]{3}{*}{ Pharmaceutical waste } & $\begin{array}{l}\text { Used and empty medicines containers and } \\
\text { used syringes }\end{array}$ & 'Pharmy' bin, usually a green or yellow container \\
\hline & $\begin{array}{l}\text { Part used or expired drugs; empty bottles; } \\
\text { vials; other pharmaceutical waste }\end{array}$ & $\begin{array}{l}\text { 'DOOP' containers (Destruction Of Old Pharmaceuticals), } \\
\text { usually green with a red lid }\end{array}$ \\
\hline & Cytotoxic medicines & $\begin{array}{l}\text { Yellow 'pharmy' bin with a black or purple top (or use } \\
\text { 'sharps' bin, as above) }\end{array}$ \\
\hline
\end{tabular}




\begin{tabular}{l|l|l|}
\hline Type of waste & Things included & Type of disposal \\
\hline Cadavers & Deceased pets and wildlife & $\begin{array}{l}\text { Release for home burial or to pet crematorium. May } \\
\text { change in the future if infectious and classified as } \\
\text { 'hazardous waste' }\end{array}$ \\
\hline Radiography chemicals & $\begin{array}{l}\text { Used or expired developer and fixer; } \\
\text { contaminated water }\end{array}$ & $\begin{array}{l}\text { Special containers and contractors needed. Regarded as } \\
\text { 'hazardous healthcare waste' }\end{array}$ \\
\hline Other 'special' waste & $\begin{array}{l}\text { Aerosols; computer monitors and TVs; } \\
\text { fridges; freezers; fluorescent light tubes }\end{array}$ & $\begin{array}{l}\text { Local council disposal sites specified for this type of } \\
\text { waste. Classified as 'hazardous waste' }\end{array}$ \\
\hline
\end{tabular}

(continued) Classification of waste, according to Control of Hazardous Waste (England and Wales) Regulations (HWR) 2005.

\section{Isolation and barrier nursing}

If an animal in the practice hospital shows signs of ill health that could be transmitted to other patients, it should be moved immediately to the isolation unit so that other patients are not exposed and put at risk. For various reasons (disease, stress, injury or not yet vaccinated) these other patients are considered to be susceptible hosts.

The methods used to control the transmission of microorganisms shed by a patient will vary.

- Good ventilation of the isolation area is essential in the control of airborne disease; therefore isolation units need to have a separate airhandling system from the rest of the clinic.

- A range of environmental disinfectants is kept in the isolation unit, providing choice in the elimination of specific microbes.

- Antiseptic hand-cleaners for use between patients and the wearing of disposable gloves when handling patients are essential.

- Although a surgical mask may not be needed routinely, wearing it as well as goggles or eye visor is recommended when nursing animals with airborne zoonoses (e.g. birds with psittacosis).

- Use of disposable paper towels for hand-drying and cleaning will further reduce transmission of infection.

- No visitors should be allowed in the isolation unit, only key nursing staff.

- The presence of all disease vectors such as flies, fleas and lice should be actively investigated and eliminated.

- Any reusable materials or equipment should be autoclaved within the isolation area before being used on other patients.

\section{Isolation unit}

- The unit must be totally self-contained, with all its own equipment for feeding, nursing and cleaning.

- One nurse should be allocated to this area and should have no other duties in the animal areas.

- A footbath should be used and clothing changed on entering and leaving the unit.

- There should be a supply of disposable protective clothing.

- Effective and appropriate disinfectants should be used.
- Personal and environmental hygiene should be strict.

- All waste from the unit should be disposed of safely.

- The patient should have no contact with other animals.

- Cages, kennels and runs should be contained within the unit.

- The unit should have its own sink/kitchen area (with hot and cold water).

- There should be a treatment table and medical supplies.

- There must be a good ventilation system (to deal with airborne microbes).

If the unit is well designed, its entrance will be separate from that of the main hospital. This enables patients with suspected contagious diseases to be taken directly to isolation.

All soiled cage papers and bedding, also other body discharges such as blood, saliva, urine, faeces and eye and nasal discharges, should be disposed of in the normal way (i.e. as clinical waste).

Apart from possible transfer of microorganisms to other patients, there may also be a risk of the transfer of zoonoses to the nursing staff; therefore it is vital that protective clothing is used (Figure 4.12).

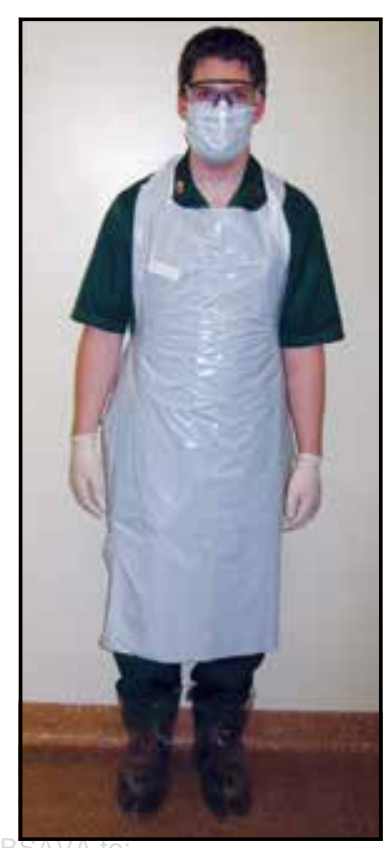

4.12 Suitable protective clothing for working in an isolation unit: disposable gloves; disposable plastic apron; disposable plastic over boots; goggles; and mask. 
In certain cases, the owners of a patient discharged from isolation should be informed that their pet may shed the infectious microorganism responsible for its disease for some time. Therefore they should limit contact with other animals during that period and be aware of hygiene issues in the case of diseases transmissible to humans (e.g. leptospirosis).

\section{Stock control}

The purpose of stock management and control is to have every drug, vaccine, or supply item always available when needed, yet not waste money acquiring and storing surplus supplies. This is a delicate balance, because the amount and trends of use of drugs and supplies can change rapidly.

If too much stock is stored, extra money and storage space are required and the stock will be paid for long before the last is used. If too little stock is kept, needed items will sometimes not be available to provide the preferred treatment for the patient, or an opportunity for the sale of a product will be missed. Close attention to stock levels of surgical supplies, pet food, pharmaceuticals, vaccines, X-ray film and other items will ensure that an adequate stock is maintained. An effective stock control system is needed to reorder and replenish items before they run out.

Most practices use one large wholesaler but may also order from other smaller suppliers (e.g. chemists, laboratories, stationery companies) and this will mean that stock control needs to be cross-referenced between several companies. Nurses need to be aware of who are the official suppliers for the practice.

\section{Responsibility for stock control}

Practice managers, veterinary nurses and occasionally reception staff may be assigned responsibility for stock control. Sometimes the responsibilities will be divided between several staff, each being responsible for a specific area. One person should be the primary person placing orders, making sure that what is received is what was ordered and invoiced.

Once a delivery of stock arrives, it should be dealt with immediately and checked thoroughly prior to being stored. The order should be checked for:

- Damage - broken glass, open boxes, wet boxes, vaccines etc. not stored at correct temperature

- Expiry dates - ensure that all are in date

- Presence of all items on the invoice or delivery note

- Price increases on the invoice

- Items requiring special storage (e.g. vaccines or controlled drugs) - ensure that these are dealt with appropriately.

\section{Storage}

Good stock control not only involves ordering and maintaining of stock; it also requires the correct storage of goods to ensure that they reach the client in good condition and that they do not perish due to incorrect storage. As a general rule the majority of stock is stored away from client access in a clean and dry environment, such as a pharmacy/dispensary area. There are exceptions to this: certain products have special requirements. For example, vaccines require refrigeration on arrival, and controlled drugs must be correctly recorded and stored in a locked cupboard. For more details of storage of medicines, see Chapter 3; for the storage of radiographic material, see Chapter 11 .

\section{Stock control systems}

Considerable money is involved in stock purchases. Much can be lost through inadequate stock control procedures. This loss may occur because the practice was billed for materials that were never received, or the practice was double-billed for an order, billed for damaged goods, or billed for more or different items than were actually received. Losses also occur because of ordering too many months' supply of perishable goods that deteriorate or go beyond the expiry date on the container and are no longer effective or legally safe to use.

Stock rotation is important to ensure that older stock is used first, thereby reducing the chance of items going out of date. All new stock should be placed under or behind existing stock, ensuring that the oldest products are at the front so that they are used first.

There are many computerized and manual stock control systems available for use within a veterinary practice, including:
- Handheld computers
- Bar coding
- Direct computer link to wholesaler
- Paper-based checklists.

In order to be accurate, computerized systems require the input of everything that is sold and used. As a result of human error or inconsistencies they are only moderately successful in providing all the stock control information needed. Manual procedures, such as taking frequent stock counts of all supplies, can go a long way to helping the computerized stock control process to be successful.

An effective stock control system should:

- Be easy to use

- Ensure that all medications and supplies are available when needed

- Reduce expenses by achieving a good turnover rate

- Provide a signal when each item needs to be ordered

- Track seasonal variations

- Track past usage

- Provide purchase cost information to keep the pricing and supply of products current

- Ensure that ordered items are actually received and back-ordered items are tracked so that over-ordering does not occur

- Make it easy to account for when and where items are used so cost can be allocated to various areas within the practice 
- Provide a procedure for checking invoices to make sure that they are accurate for amounts ordered and prices quoted

- Allow the practice to obtain the best prices available, identify expired or outdated items and return to suppliers for credit as required.

Definitions of terms used in stock control are given in Figure 4.13.

\begin{tabular}{l|l}
\hline Delivery note & $\begin{array}{l}\text { Arrives with the goods ordered and can } \\
\text { be used to check goods received }\end{array}$ \\
\hline Invoice & $\begin{array}{l}\text { Gives details of goods received with a } \\
\text { breakdown of costs and balance owed }\end{array}$ \\
\hline Invoice number & $\begin{array}{l}\text { The invoicing company's reference } \\
\text { number }\end{array}$ \\
\hline Order number & The practice's reference number \\
\hline Unit price & Price per individual item \\
\hline Recommended \\
retail price & Price at which products should be sold \\
\hline Terms of delivery & $\begin{array}{l}\text { Supplier's delivery terms (e.g. 'balance } \\
\text { payable on delivery of goods') }\end{array}$ \\
\hline Terms of payment & $\begin{array}{l}\text { Supplier's payment terms (e.g. 'within } \\
30 \text { days of receipt of invoice') }\end{array}$ \\
\hline Credit note & $\begin{array}{l}\text { Issued to allow products up to that } \\
\text { value to be purchased without charge }\end{array}$ \\
\hline
\end{tabular}

4.13 Terms used in stock control.
As with all business documents, records should be stored in a logical manner so that they can be easily found if required and only the appropriate staff (e.g. person responsible for ordering, practice manager and practice principal) should have access to the information.

\section{Rules of good stock control}

- Check all goods against the delivery note.

- Check delivery note against original order.

- Unpack all stock immediately upon receipt.

- Dispose of all packing immediately and correctly (e.g. clinical waste in yellow bags).

- Sort out special storage products (e.g. vaccines, insulin, controlled drugs).

- Keep minimum stock level records and reorder when stock reaches this.

- Rotate all stock.

- Carry out regular stock audits.

- Maintain auditable records and security of these.

\section{Further reading}

Platten D (2007) Management of an animal ward. In: BSAVA Manual of Practical Animal Care, ed. P Hotston Moore and A Hughes, pp. 88-107. BSAVA Publications, Gloucester

Monsey $L$ (2007) Maintaining animal accommodation. In: BSAVA Textbook of Veterinary Nursing, 4th edn, ed. DR Lane et al., pp. 210-227. BSAVA Publications, Gloucester 